\title{
Adhesion analysis of waste cork dust as filler for bituminous mixtures
}

\author{
A.R. Pasandín \\ Universidade da Coruña (UDC), E. T. S. I. Caminos, Canales y Puertos, Department of Civil \\ Engineering, La Coruña, Spain \\ J.J. Galán-Díaz \\ Universidade da Coruña (UDC), E. T. S. I. Caminos, Canales y Puertos, Department of Naval and \\ Industrial Engineering, La Coruña, Spain
}

I. Pérez

Universidade da Coruña (UDC), E. T. S. I. Caminos, Canales y Puertos, Department of Civil Engineering, La Coruña, Spain

\begin{abstract}
Suberin is a biopolymer that can be found in high amounts in natural cork. As is well known, polymers can be used as bitumen modifiers to improve the properties of bituminous mixtures. This paper describes laboratory adhesion analysis that was conducted to analyse the use of waste cork dust as a filler in hot-mix asphalt (HMA). The performance of the waste cork dust as a filler was compared with that of a typically used natural filler and with Portland cement. These three fillers were characterized by their grain size distributions, morphological studies, and X-ray fluorescence spectroscopy experiments. The adhesion between the aggregates and the binder was analysed using two adhesion tests: a "boiling water test" and using the "rolling bottle method". Both tests led to the same result: the waste cork dust was a better filler than the natural filler.
\end{abstract}

\section{INTRODUCTION}

Cork is the name given to the bark of the cork oak (Quercus Suber L.). Portugal has 34\% of the world's cork oaks, followed by Spain with $27 \%$ (APCOR n.d.).

Cork is a $100 \%$ natural and sustainable material because once the bark is removed from the cork oak, it is regenerated again, and a new bark can be extracted every nine years (Jardin et al. 2015). Using different products (e.g., cork stoppers for wine), 280,000 tonnes of cork are consumed annually (Cordeiro et al. 1998). Of this, approximately $20-30 \%$ is waste, which is mainly in the form of cork dust. This fraction currently lacks industrial interest; thus, it is usually employed for combustion to produce energy. Thus, there is a certain granulometric fraction of waste cork with the potential for reuse.

The cork contains $45 \%$ of the biopolymer, suberin (APCOR n.d.). The effects derived from the use of polymers as bitumen-modifying agents are well known: a decrease in thermal susceptibility with a consequent larger resistance to permanent deformation as well as fatigue and temperature cracking (Sun \& Lu 2006). Considering the beneficial action of polymers in asphalt and that there is a large amount of waste cork dust (rich in suberin biopolymer), there is a great potential to use this waste in bituminous mixtures, not only as a bitumen modifier but also as an aggregate and mineral filler.

To date, only few researchers have investigated the use of cork in bituminous mixtures. There has been evidence of several investigations in which cork is used to modify bitumen. For example, although it does not fit into the field of road paving, a patent (US 2099131 A) is reported, in which a mastic of bitumen and granulated cork is used to make the top of tiles (Miller 1937).

Regarding the use of cork as an aggregate, the work by Pereira et al. (2013) stands out. These researchers replaced 5\% by volume of natural aggregate with cork particles from $1 \mathrm{~mm}$ to $4 \mathrm{~mm}$ to manufacture hot-mix asphalt (HMA) type AC14bin. The mixtures that were obtained showed 
an excellent resistance to permanent deformation, adequate water sensitivity, lower stiffness, and fatigue life that is lower than that of the control mixture.

However, to date, no study has been published in which waste cork dust has been used as a filler for the manufacture of HMA.

\section{AIMS AND SCOPE}

The objective of this investigation was to analyse the feasibility of using waste cork dust from the manufacturing of wine stoppers as a filler for HMA. The motivation of this investigation was twofold. First, we aimed to solve the environmental problems arising from the energy recovery of these types of wastes. Second, cork is rich in suberin, a vegetable biopolymer that can improve the performance of bituminous mixtures. Hence, we analysed the possible binderaggregate adhesion improvements that the use of waste cork dust may entail. To comply with this objective, the characteristics and affinities of the three fillers were compared: waste cork dust, natural filler, and Portland cement.

\section{MATERIALS AND METHODS}

\subsection{Materials}

Next, we describe the materials used in this investigation.

\subsubsection{Aggregates}

A typical siliceous commercial quarry aggregate was used in this study, which was a crushed hornfel. The hornfel was supplied by a local contractor. The main properties of the hornfel were evaluated. Table 1 shows the bulk specific gravity $(\rho a)$, the water absorption $\left(W_{24}\right)$, the sand equivalent (SE), the Los Angeles abrasion coefficient (LA), and the flakiness index (FI).

Table 1. Main properties of the hornfels

\begin{tabular}{lll}
\hline Property & Standard & Results \\
\hline$\rho \mathrm{\rho}\left(\mathrm{g} / \mathrm{cm}^{3}\right)$ & EN-1097-6 (AENOR 2014) & 2.65 \\
$\mathrm{WA}_{24}(\%)$ & EN 1097-6 (AENOR 2014) & 0.7 \\
$\mathrm{FI}(\%)$ & EN 933-3 (AENOR 2012a) & 13 \\
$\mathrm{LA}(\%)$ & EN 1097-2 (AENOR 2010a) & 20 \\
\hline
\end{tabular}

\subsubsection{Filler}

As mentioned above, three types of filler were used in this preliminary investigation: waste cork dust, natural filler, and Portland cement type CEM I 52.5 R.

\subsubsection{Bitumen}

A typically used penetration-grade bitumen B50/70 was selected for this investigation. Table 2 shows the basic properties of this bitumen.

Table 2. Main properties of the bitumen

\begin{tabular}{lll}
\hline Property & Standard & Results \\
\hline Penetration grade $(0.1 \mathrm{~mm})$ & EN-1426 (AENOR 2015a) & 59 \\
Ring and ball softening point $\left({ }^{\circ} \mathrm{C}\right)$ & EN 1427 (AENOR 2015b) & 50.7 \\
\hline
\end{tabular}

\subsection{Methods}

Next, the methods used in this investigation are described. 


\subsubsection{Filler characterization}

Some filler properties may affect the binder-aggregate adhesion. In this regard, the following properties were analysed:

- The grain size distributions of the three filler grains were analysed following the EN933-10 (AENOR 2010b). Air jet sieving was used to perform this test.

- A qualitative evaluation of the geometric characteristics of the filler particles was conducted. This morphological study was conducted by means of scanning electron microscopy (SEM).

- The elemental composition of the three filler particles was determined via X-ray fluorescence spectroscopy (XRF) (Bruker S4 Pioneer fluorescence spectrometer).

\subsubsection{Binder-aggregate adhesion}

To analyse the affinity between the aggregate and the binder, two types of tests were carried out. First, a boiling water test was performed following the ASTM D3625 standard (ASTM 2005) Second, a test of the rolling bottle was performed according to the procedure described in the EN 12697-11 standard (AENOR 2012b).

In the boiling water test, a sample of loose bituminous mixture made with an aggregate fraction of 8/11.2 mm was left for 10 min in boiling water, and we analysed the amount of bitumen that detached from the surface of the aggregate. The visual observation was made just when the mixture separated from the water and after $24 \mathrm{~h}$. This second observation was made because during the entire time period, the loose mixture became dry and the surface of the aggregate that remained coated could be observed with higher accuracy.

In the rolling bottle test, a sample of loose bituminous mixture, which was also made with the 8/11.2 $\mathrm{mm}$ aggregate, was introduced into a bottle with distilled water. The bottle rotated at a constant speed for several hours. The amount of bitumen that was released from the surface of the aggregate was analysed after $24 \mathrm{~h}$ of rotation.

In both tests, the greater the proportion of aggregate surface that remained coated with bitumen, the better adhesion between the aggregate and the binder and, therefore, the better expected performance the bituminous mixture will have against water.

In both tests, to analyse the influence of the natural filler, cork dust, and cement, a $4 \%$ filler (dry aggregate) was used.

In addition, for the boiling water test, Kennedy et al. (1984) indicated that loose asphalt mixtures that retain less than $70 \%$ of bitumen on the aggregate surface are moisture susceptible. Kim \& Coree (2005) indicated that this percentage must be 95\%. In the case of the rolling water test, there are no requirements on the percentage of aggregate surface that should be coated with bitumen after the rotation periods. Therefore, this test is useful only for comparison.

\section{RESULTS AND DISCUSSION}

\subsection{Filler characterization}

Figure 1 shows the grain size distribution of the three tested fillers according to the air jet sieving results. This figure also includes the upper and lower limit specified by the Spanish General Technical Specifications for Road and Bridges (PG-3) (MFOM 2008), in which the grain size of the filler must be inscribed to be suitable for use in bituminous mixtures.

As shown in Figure 1, the three fillers (the waste cork dust, the natural filler, and the cement) are suitable for the manufacture of bituminous mixtures according to the PG-3. Nevertheless, Figure 1 also shows that the natural filler is finer grade than the cement and that the cement is finer grade than the waste cork dust. The filler activity is related to fineness because a finer filler typically has a higher activity. Thus, we expected a lower activity in the case of the waste cork dust. This could negatively affect the physical affinity between the aggregate and the binder. 


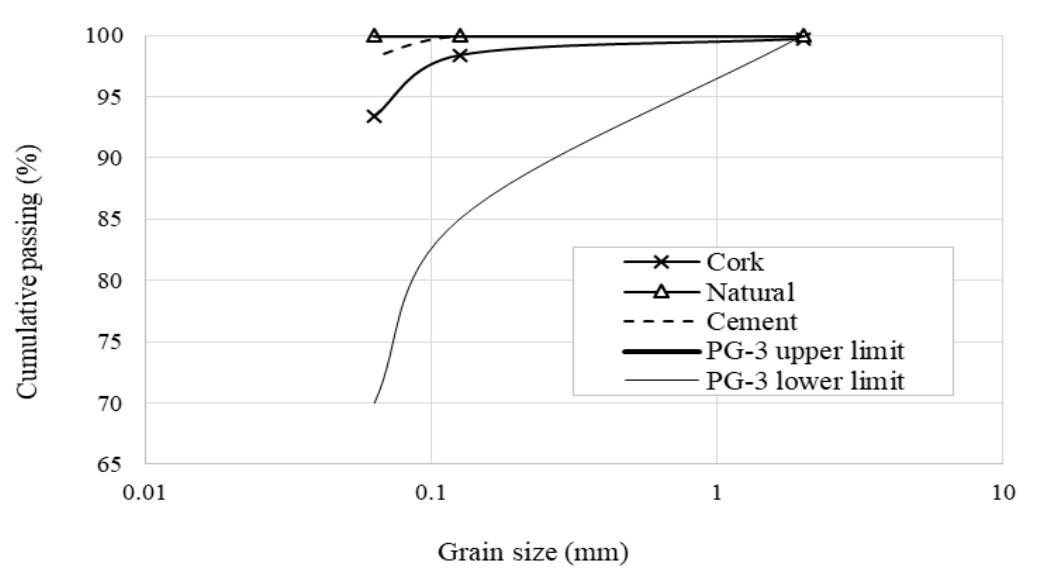

Figure 1. Grain size distribution of the three fillers

Figure 2 show the SEM images of the three fillers. As shown in the figure, the waste cork dust (Fig. 2a) appears to be less caked with finer scales than the natural filler (Fig. 2b) and the Portland cement (Fig. 2c). This property could positively affect the affinity between the binder and the aggregate because it is easier to form heterogeneous mixtures if the filler does not tend to agglomerate.
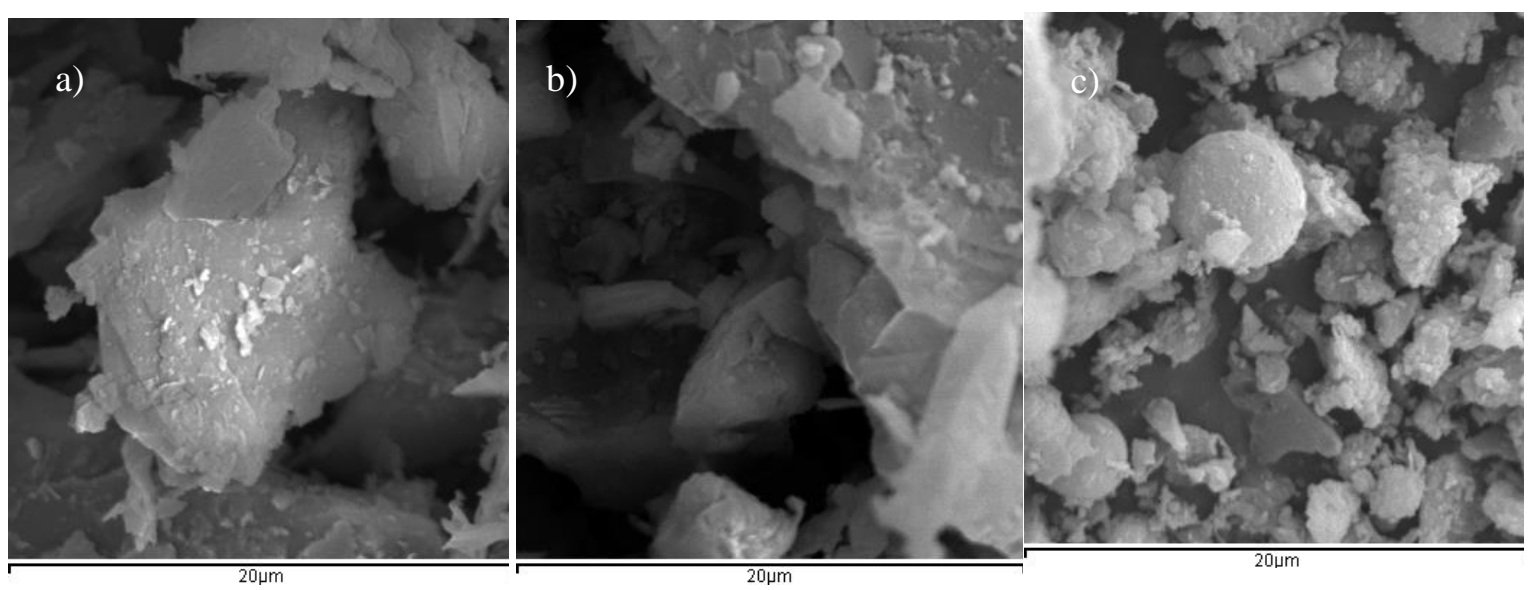

Figure 2. SEM images of a) the waste cork dust, b) natural aggregate and c) Portland cement

A high $\mathrm{SiO}_{2}$ percentage is usually associated with poor adhesion (Bagampadde 2004). In this regard, the XRF test showed that the natural filler has $57.4 \%$ of $\mathrm{SiO}_{2}$, the waste cork dust has $56.3 \%$ of $\mathrm{SiO}_{2}$, and the Portland cement has $17.7 \%$ of $\mathrm{SiO}_{2}$. Thus, it is expected that the binder aggregate adhesion is better when the Portland cement is the filler, followed by the waste cork dust and then the natural filler.

A high $\mathrm{CaO}$ percentage is associated with adequate adhesion (Bagampadde 2004). The XRF test indicated that the natural aggregate has $0.39 \%$ of $\mathrm{CaO}$, the waste cork dust has $0.45 \%$ of $\mathrm{CaO}$, and the Portland cement has $58.0 \%$ of $\mathrm{CaO}$. Again, the $\mathrm{CaO}$ percentages confirm the above expected adhesion results.

\subsection{Binder-aggregate adhesion}

Figure 3 shows the results of the boiling water test for the three tested fillers: waste cork dust, natural filler, and Portland cement. As mentioned above, two visual observations were made: when the loose mixture left the water and $24 \mathrm{~h}$ later. As mentioned above, the second observa- 
tion was the one that was considered the most appropriate because the sample was dry and it was easier to appreciate the degree of coating of the aggregate by the bitumen. According to this last observation, Figure 3 shows that the better coating results were obtained when Portland cement was used as the filler (93\%), followed by the waste cork dust (90\%) and the natural filler (78\%). The results obtained when the waste cork was used as the filler were very similar to those obtained with the Portland cement.

Both fillers showed results higher than the $70 \%$ required by some authors, but none of them showed results higher than the $95 \%$ required by other authors. Nevertheless, results for the use of Portand cement and waste cork dust as fillers were very close to this percentage.

Figure 4 shows the results obtained for the rolling bottle test for the three tested fillers. As shown, the use of waste cork dust as the filler resulted in higher coating results (79.4\%) after 24 $\mathrm{h}$ of rotation. The natural filler was second $(78.9 \%)$, and the Portland cement as the filler was third $(66.7 \%)$.

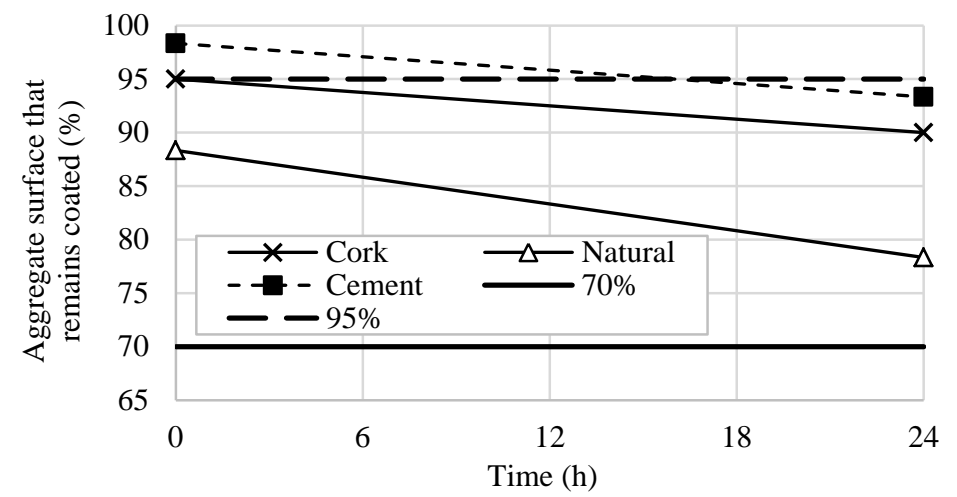

Figure 3. Boiling water test results

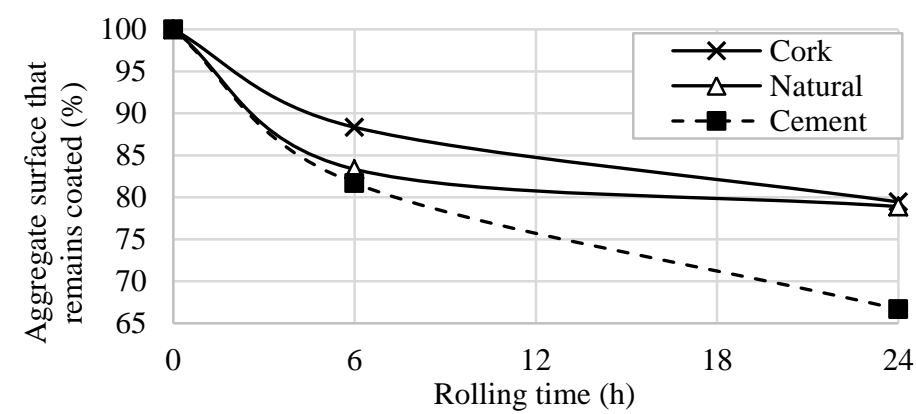

Figure 4. Rolling bottle method results

Clearly, the different mechanisms that prevailed in each of the two tests produced some differences in the results. The boiling water test results are adequate to represent the effect that high temperatures can have on bituminous mixtures in warm climates. High temperatures can reduce the viscosity of the binder and affect its adhesion. The rolling bottle method results are adequate to represent the effect of mechanical damage on the adhesion in cold climates. In the case of the use of waste cork dust as a filler, both tests yielded very satisfactory results in terms of aggregate-binder adhesion. Thus, this filler could be used in both warm and cold climates.

\section{CONCLUSIONS}

The use of waste cork dust as a filler for the manufacture of bituminous mixtures is suitable in terms of grain size distribution and in terms of aggregate-binder adhesion. This is the case in both cold and warm climates. Nevertheless, further investigation is needed. 


\section{ACKNOWLEDGEMENTS}

The authors would like to thank the Servizos de Apoio á Investigación (SAI) (Research support services) of the Universidade da Coruña (UDC) for performing the SEM and XRF tests. The authors would also like to thank Probigasa for supplying the natural aggregates and Repsol for supplying the bitumen.

\section{REFERENCES}

AENOR. Asociación Española de Normalización y Certificación. UNE-EN 933-3 Tests for geometrical properties of aggregates. Determination of particle shape. Flakiness index. Madrid, Spain, 2012a (in Spanish).

AENOR. Asociación Española de Normalización y Certificación. UNE-EN 1097-2 Tests for mechanical and physical properties of aggregates. Methods for the determination of resistance to fragmentation. Madrid, Spain, 2010a (in Spanish).

AENOR. Asociación Española de Normalización y Certificación. UNE-EN 1097-6 Tests for mechanical and physical properties of aggregates. Determination of particle density and water absorption. Madrid, Spain, 2014 (in Spanish).

AENOR. Asociación Española de Normalización y Certificación. UNE-EN 1426 Bitumen and bituminous binders. Determination of needle penetration. Madrid, Spain, 2015a (in Spanish).

AENOR. Asociación Española de Normalización y Certificación. UNE-EN 1427 Bitumen and bituminous binders. Determination of the softening point. Ring and Ball method. Madrid, Spain, 2015b (in Spanish).

AENOR. Asociación Española de Normalización y Certificación. UNE-EN 12697-11 Bituminous mixtures. Test methods for hot mix asphalt. Determination of the affinity between aggregate and bitumen. Madrid, Spain, 2012b (in Spanish).

AENOR. Asociación Española de Normalización y Certificación. UNE-EN 933-10 Tests for geometrical properties of aggregates - Part 10: Assessment of fines - Grading of filler aggregates (air jet sieving). Madrid, Spain, 2010b (in Spanish).

APCOR. (n.d.). http://www.apcor.pt/ (accessed 10 december 2018).

ASTM. D 3625-96. Standard Practice for Effect of Water on Bituminous-Coated Aggregate Using Boiling Water, 2005.

Bagampadde, U. "On investigation of stripping in bituminous mixtures". Tesis doctoral. Karlstad University, 2004.

Cordeiro, N., Belgacem, M.N., Silvestre, A.J.D., Neto, C.P., Gandini, A. (1998). Cork suberin as a new source of chemicals: 1. Isolation and chemical characterization of its composition.International Journal of Biological Macromolecules, 22(2), 71-80.

Jardin, R.T., Fernandes, F.A.O., Pereira, A.B., de Sousa, R.A. (2015). Static and dynamic mechanical response of different cork agglomerates. Materials \& Design, 68, 121-126. https://doi.org/10.1016/j.matdes.2014.12.016

Kennedy, T.W., Roberts, F.L., Anagnos, J.N. (1984). Texas boiling test for evaluating moisture susceptibility of asphalt mixtures (No. FHWA-TX-85-63+ 253-5). Center for Transportation Research, Bureau of Engineering Research, University of Texas at Austin.

Kim, S., Coree, B.J. (2005). Evaluation of hot mix asphalt moisture sensitivity using the Nottingham asphalt test equipment (No. IHRB Project TR-483). Iowa State University. Center for Transportation Research and Education.

MFOM, Ministry of Public Works. Article 542 (Asphalt Concrete) of the General Technical Specifications for Road and Bridge Works (PG3) from the Spanish Ministry of Public Works. Madrid, Spain, 2008 (in Spanish).

Miller, S. P. (1937). U.S. Patent No. 2,099,131. Washington, DC: U.S. Patent and Trademark Office.

Pereira, S.M., Oliveira, J.R., Freitas, E.F., Machado, P. (2013). Mechanical performance of asphalt mixtures produced with cork or rubber granulates as aggregate partial substitutes. Construction and Building Materials, 41, 209-215. https://doi.org/10.1016/j.conbuildmat.2012.12.005

Sun, D., Lu, W. (2006). Phase morphology of polymer modified road asphalt. Petroleum science and technology, 24(7), 839-849. 10.1081/LFT-200043780 